\title{
FTIR reflectance of selected minerals and their mixtures: implications for ground temperature-sensor monitoring on Mars surface environment (NASA/MSL-Rover Environmental Monitoring Station)
}

\author{
M. Paz Martín-Redondo, Eduardo Sebastian Martínez, M. Teresa Fernández Sampedro, Carlos Armiens, \\ Javier Gómez-Elvira and Jesus Martinez-Frias*
}

\author{
Received 9th March 2009, Accepted 19th May 2009 \\ First published as an Advance Article on the web 2nd June 2009 \\ DOI: 10.1039/b904737a
}

\begin{abstract}
The Rover Environmental Monitoring Station (REMS) is one of NASA/MSL's instruments, which has been designed for measuring ambient pressure, humidity, wind speed and direction, UV radiation, and air and ground temperature (GT). The GT-sensor is dedicated to measure the real temperature of the Martian surface, integrating the IR energy coming from the ground. The existing IR spectral data of Martian dust, rocks and sediments allow for comparing the Martian spectra with the spectra of different terrestrial minerals and lithologies, and those of their alteration and weathering products. The FTIR reflectance of a set of selected astrobiologically significant minerals (including oxides, oxi/hydroxides, sulfates, chlorides, opal and clays) and basalt (as the main and most widespread volcanic Martian rock) was measured, considering different mixing amounts, and covering the specific working wavelength range of the REMS' GT-sensor. The results obtained show important percentage increases or decreases of reflectance in the entire wavelength range (e.g. basalt-hematite $v$ s. basalt-magnetite) and specific variations limited to some spectral bands (e.g. basalt-smectite $v s$. basalt-jasper). The basalt reflectance percentage increases or decreases, even up to $100 \%$, depending on the mixing of the different minerals. This unequivocally confirms the need for considering the chemical-mineralogical assemblages (and their textures) for any investigation and interpretation of Mars surface environment. Some complementary applications of this research on our planet, either in relation to the specific performances and characteristics of the GT-sensor autonomous recalibration system, or those oriented to carrying out similar studies on different types of terrestrial environmental settings, are also described.
\end{abstract}

\section{Introduction}

The current Mars exploration roadmap is characterized by the emerging concept of "habitability", which is mainly marked by the classical "follow-the-water strategy", the additional physical-chemical information that minerals and their paragenetic associations offer about the past and present Martian environmental systems, and the search for biomarkers. It is well known that IR spectroscopy gives direct information of the existence of $\mathrm{H}_{2} \mathrm{O}$ or $\mathrm{OH}$, either as free $\mathrm{H}_{2} \mathrm{O}$ or bonded within hydrated minerals, through the measurement of the fundamental $\mathrm{H}-\mathrm{O}-\mathrm{H}$ vibrational stretching modes near $3 \mu \mathrm{m}$, as well as overtone modes, such as the $\mathrm{O}-\mathrm{H}$ (hydroxyl) stretch near $1.4 \mu \mathrm{m}$, and the combination $\mathrm{H}-\mathrm{O}-\mathrm{H}$ bend/stretch mode near $1.9 \mu \mathrm{m} .{ }^{1,2}$ Reflectance spectroscopic studies have provided some of the most remarkable advances in our understanding of the Mars surface environment, such as detecting the presence of various types of water-related minerals. ${ }^{3-5}$ However, much is still unknown about Martian chemical-mineralogical assemblages, which is fundamental to interpreting its entire geological

Centro de Astrobiologia, CSICIINTA, Associated to the NASA Astrobiology Institute, Ctra de Ajalvir, km. 4, 28850 Torrejón de Ardoz, Madrid, Spain.E-mail: martinezfj@inta.es; Fax: +34 91-5201621 history, and environmental (and paleoenvironmental) settings. $^{5-8}$

NASA's Mars Science Laboratory (MSL) is a rover that will assess whether Mars ever was, or is still today, an environment able to support microbial life. ${ }^{9}$ It is the first mission with an environmental station located on the rover and with a mission's duration of one Martian year, which allows for the study of Mars seasons. Its launch is scheduled for the fall of 2011. The Rover Environmental Monitoring Station (REMS) is one of the MSL's instruments, developed by the Spanish "Centro de Astrobiología (CSIC-INTA)" in collaboration with EADS-Crisa, the Universidad Politécnica de Cataluña, the Finish Meteorological Institute, NASA Ames Research Center, the University of Michigan, the Universidad de Alcalá and the California Institute of Technology. REMS will measure and provide daily and seasonal reports on atmospheric pressure, humidity, ultraviolet radiation at the Martian surface, wind speed and direction, air temperature, and ground temperature (GT) around the rover. ${ }^{10}$ Specifically, the GT-sensor is devoted to measuring the kinematic temperature of the Martian surface, integrating the IR energy coming from the ground. An important point related with the temperature of the Mars surface environment is that it can be influenced by different factors (among others, putative radioactive heat sources, mantle heat flow, surface temperature, thermal conductivity and, particularly, the mineralogy of the Martian regolith). ${ }^{11}$ 
The existing IR spectral data of Martian dust, rocks and sediments allow for comparing the Martian spectra with spectra of different terrestrial minerals and lithologies, and those of their alteration and weathering products. These spectral comparisons have not only been focused on laboratory studies. ${ }^{12-14} \mathrm{~A}$ Fourier transform infrared spectrometer (FTIR) for field studies, that serves as a prototype for future Mars science applications, was recently developed, ${ }^{15}$ and IR spectrometry was, for instance, specifically used for the study of drill core samples in a drilling exercise simulating a future Mars mission (M.A.R.T.E. project) ${ }^{16,17}$ Nowadays, we know that the Martian regolith is made up of an apparently homogenized dust having (broadly) basaltic composition, with admixed local rock components, oxides (e.g. hematite), water-bearing phyllosilicates and salts (mainly sulfates). Quartzofeldspathic materials also have been identified, and carbonate-bearing rocks have been recently detected. In this context, the FTIR reflectance of a set of selected astrobiologically significant minerals (including oxides, oxi/ hydroxides, sulfates, chlorides, opal and clays) and basalt (as the main and most widespread volcanic Martian rock) was measured, considering different mixing amounts, and covering the working wavelength range of the REMS' GT-sensor.

\section{Mars temperature constraints and GT-sensor features}

Thanks to previous NASA missions (e.g. Viking, Pathfinder, MER, Phoenix), it is well known that the temperature at the planet's surface varies widely during the course of a Martian day, from about $-87{ }^{\circ} \mathrm{C}$ just before dawn to about $-20{ }^{\circ} \mathrm{C}$ in the afternoon. Near-surface atmospheric temperature at landing sites (e.g. Gusev crater, Meridiani Planum) ranges from $-100^{\circ} \mathrm{C}$ to $0{ }^{\circ} \mathrm{C}$. Surface temperature averages $-53{ }^{\circ} \mathrm{C}$; varies from $-128{ }^{\circ} \mathrm{C}$ during polar night to $27{ }^{\circ} \mathrm{C}$ at the equator during midday at the closest point in orbit to the Sun. However, the causes of many significant temperature variations still remain unexplained. For instance, Martian surface temperatures and albedos were measured from ground-based IR spectroscopy, between September and December 1988. As a result, the measured surface temperatures seemed to be higher than the Viking temperatures measured in 1977, and closer to the theoretical temperatures calculated from Viking 1976 (primary mission). ${ }^{18}$ Much more recent measurements by Phoenix (25 May 2008) indicate that Martian regolith temperatures (polar latitudes) ranged from $-20^{\circ} \mathrm{C}$ to $-92^{\circ} \mathrm{C}$. Shadowing by the robotic arm, the robotic arm camera, and scoop are evident around 1300 local mean solar time. ${ }^{19}$

Some important problems regarding the measurement of the temperature are associated with the uncertainty in the emissivity of the target,$^{20}$ environment reflections ${ }^{21}$ and sensor degradation when operating in adverse or remote environments. In our case, the effect of Mars' dusty atmosphere over the GT-sensor shall be compensated using the recalibration system, while the radiated heat power by the Martian surface depends mainly on three factors: (1) the temperature of the focused area; (2) the unknown average emissivity, $\varepsilon$, of the ground, or, what is the same, its capacity to emit IR energy, and finally (3) the average reflectivity, $r$, of the ground, that shows how it reflects IR energy coming from the environment, mainly from the rover. Assuming that the Martian ground IR reflectivity is equal to $r=1-\varepsilon$, and the typical emissivities of Martian soils are different from one, the expression of the ground radiated heat power is obtained as the sum of the emitted and the reflected powers, $P_{\text {radiated }}=P_{\text {emitted }}+$ $P_{\text {reflected }}$, i.e., $P_{\text {radiated }}=\varepsilon A E_{\text {ground }}+(1-\varepsilon) A F E_{\text {rover }}$, where $A$ and $F$ are known values of the area of the ground and the view factor between the rover and the ground, respectively, and $E$ is the heat flux power calculated based on Planck's law and the temperature of the body. Therefore, the estimation of ground temperature depends on the rover heat flux power and ground emissivity. Typical average emissivity values of Martian soils from 6 to $25 \mu \mathrm{m}$ vary between 0.9 and $1,{ }^{20}$ introducing an important uncertainty in the power emitted and reflected by the ground. This justifies the necessity of a specific study of the IR reflectance properties associated to different kinds of Martianlike minerals and rocks, also considering that Martian surface composition is complementarily provided by other NASA/MSL instruments. ${ }^{9}$

The GT-sensor is a pyrometer dedicated to measure the real or kinematic temperature of the Martian surface with an accuracy better than $5{ }^{\circ} \mathrm{C}$ within a ground temperature range from $-135^{\circ} \mathrm{C}$ to $40{ }^{\circ} \mathrm{C}$. The retrieval of the surface temperature of Mars is essential to develop environmental models of the Martian atmosphere-surface boundary layer. ${ }^{22}$ The GT-sensor achieves ground temperature measurements integrating the radiated power of the Martian surface in three different infrared wavelength channels: $8-14 \mu \mathrm{m}, 16-20 \mu \mathrm{m}$ and $14.5-15.5 \mu \mathrm{m}$. The first two bands are optimized for the higher and lower Martian ground temperature range, and their output signals can be combined in order to apply colour pyrometry techniques. This can help, under some specific circumstances, to estimate the emissivity of the Martian ground. The third band is centred in the $\mathrm{CO}_{2}$ absorption band, the main component of the Martian atmosphere. This allows the determination of the residual influence that the atmosphere may have in the other two thermopile's bands. The three bands are selected avoiding wavelengths below $6 \mu \mathrm{m}$, in which solar radiation cannot be neglected.

GT-sensor selected detectors are the thermopiles TS- 100 of the company IPHT Jena, encapsulated inside a TO-5 photocell and looking directly to the ground without any optical system, just the thermopile filter built to the specification and pre-bonded onto them as the thermopile window. The thermopiles have an internal thermistor sensor to measure the temperature of their can base, which acts as a temperature reference of the cold junction of the thermocouples, as well as a non-corrosive, insulator and transparent filling atmosphere. These detectors have the advantage that they can work at almost any operational temperature, are small, lightweight, comparatively cheap, and sensible to all the IR spectra. Taking into account the restricted resources available for REMS, there is hardly any alternative to thermopiles. Contrary, thermopiles are not standard parts for space or military applications. Therefore, at present no formally space qualified thermopile sensors exist. It should be noted here that the IRTM (Infrared Thermal Mapper) experiment on the VIKING mission ${ }^{20}$ and the MUPUS-TP (Multipurpose Sensors for Surface and Sub-Surface Science-Thermal Probe) experiment on the ROSETTA mission ${ }^{23}$ have proven the suitability of this kind of detector to measure low object temperatures under space conditions. The GT-sensor is allocated in a boom (Fig. 1), which is placed in the NASA/MSL rover mast at $1.6 \mathrm{~m}$ height. The 


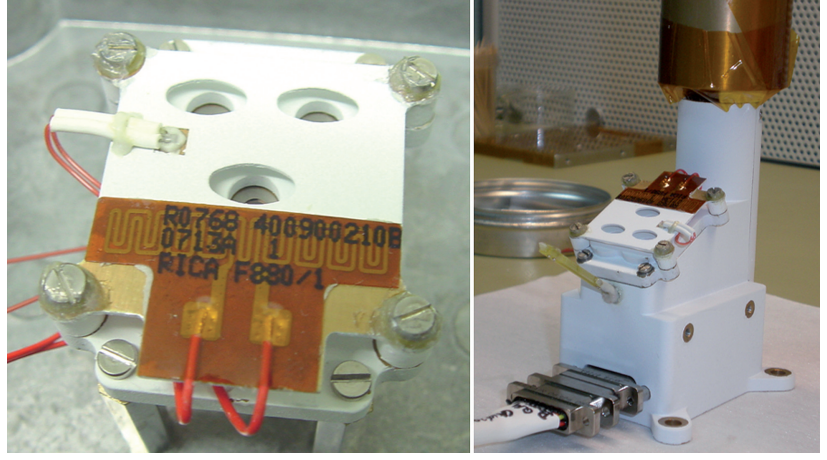

Fig. 1 Flight model of REMS. Ground temperature-sensor (left), showing the Pt1000 (Platinum thermistor that have a resistance of $1000 \Omega$ at $0{ }^{\circ} \mathrm{C}$ ), the calibration plate, the thermopiles holes and the heater. Flight model finally assembled at the REMS boom (right).

boom has the form of a small arm $150 \mathrm{~mm}$ long, and it also hosts the electronics dedicated to amplify thermopiles' signals. The GT-sensor mechanical structure is an ad hoc design (Fig. 1). The sensor is composed by a metal piece that hosts the IR detectors, used as a thermal mass to ensure an acceptably low drift in the thermopiles' temperature, and a simple low mass and high emissivity calibration plate without moving parts, whose main goal is to compensate the detector degradation due to the deposition of dust over its window. To our knowledge, this is a pioneering recalibration system for pyrometers designed to compensate the degradation of the sensor in a dusty environment, avoiding complicated and costly commercial air purge systems to keep sensor windows free of dust. Again, from REMS available resources, there is not any other alternative to the proposed recalibration system as it is not possible to use chopping systems as described in Kieffer et al.,$^{20}$ GTS focuses on a large ellipsoidal surface area of around $100 \mathrm{~m}^{2}$, measuring its average temperature. This area is far enough from the rover to minimize its influence (the MSL rover Radioisotope Thermoelectric Generator (RTG) can reach temperatures of $200 \mathrm{~K}$ over the ground heating the closest ground surface).

\section{Experimental}

A set of seven minerals were selected for the experiments, from verified standards (SARM, NCS, USGS) and Mars analogs (e.g. Rio Tinto, Jaroso, Atacama) (Fig. 2): hematite, goethite, magnetite, jarosite, halite, smectite/montmorillonite and opal (all of them are minerals which have already been found on Mars). The mineral composition was previously verified by XRD (Seifert XRD 3003 TT). Samples were cut into small pieces, grounded in an agate mortar, and sieved to get a powder smaller than $45 \mu \mathrm{m}$ (in accordance with Martian regolith dust). All mineral powders were dried in order to fit the Mars arid surface conditions before their final analysis using a Nicolet Nexus FT-IR (Thermo), using a Reflectance accessory (Praying Mantis Diffuse Reflection attachment, HARRICK). Binary and ternary mixtures were performed, covering different percentages and using basalt (BDR-2, USGS) as general matrix/groundmass for the mineral combinations, as follows: (1) $75 \%$ basalt (B) $-25 \%$ selected mineral (SM); (2) 50\% B-50\% SM; (3) 25\% B-75\% SM;

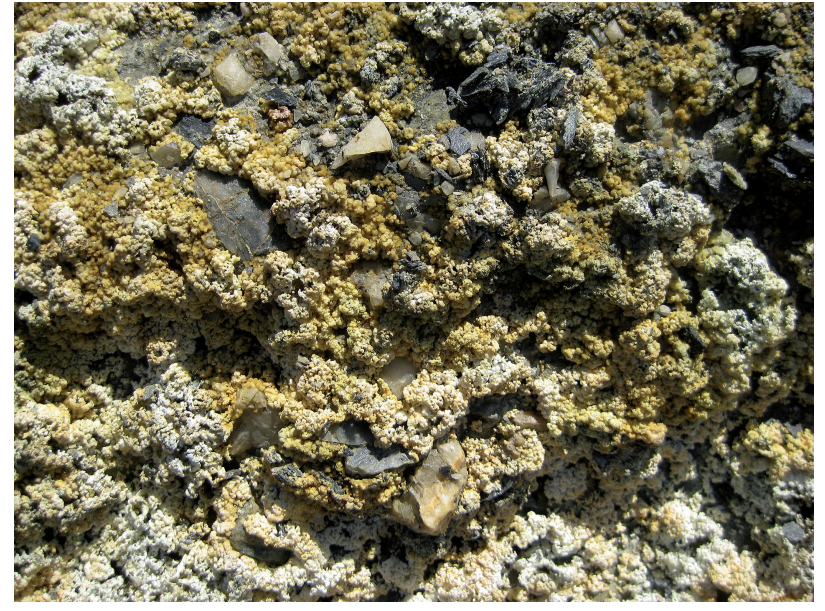

Fig. 2 Crust of jarosite and other sulfates. (Jaroso Hydrothermal System, SE Spain, Jarosite World Type Locality). Jarosite was discovered on Mars in 2004, and it has proven to have a great environmental and astrobiological importance, for its relation with liquid water. The Jaroso area is an interesting Mars analog, where different mineralogical studies (e.g. FTIR, Raman) have been carried out. ${ }^{29-31}$

(4) $50 \%$ B-25\% selected mineral 1 (SM1)-25\% selected mineral 2 (SM2); (5) 25\% B-50\% SM1-25\% SM2, and (6) 25\% B-25\% SM1-50\% SM2. All spectra were recorded, covering the working wavelength range of the REMS' GT sensor, from 3.34 to 25 microns, with a resolution of $4 \mathrm{~cm}^{-1}$.

\section{Results and discussion}

The results obtained indicate significant percentage increases or decreases of reflectance in the whole wavelength range (e.g. basalt-hematite vs. basalt-magnetite) and specific variations restricted to some spectral bands (e.g. basalt-smectite $v s$. basaltopal). Specifically, the spectral data show that the basalt reflectance percentage increases or decreases, even up to $100 \%$, depending on the mixing of the different minerals. Likewise, large differences between the oxides, hematite and magnetite, are observed: all of the basalt bands increase drastically in correspondence with the increase of the amount of hematite. Contrarily, the results with magnetite are totally the opposite. Also, if smectite and opal are compared, no significant changes in the basalt signal are detected with the former, but big changes, ranging between 3.4 and 15 microns, are observed with the opal. The mixing of basalt and sulfates (gypsum or jarosite) displays similar effects, decreasing, in most of the range, the percentage on reflectance. Nevertheless, there is a band for the gypsum, between 0 and 10 microns, which increases the basalt sign more significantly than for the jarosite.

In short, the following variation patterns are observed: (1) for basalt-magnetite or basalt-hematite, the variation of the reflectance percentage does not follow a progressive pattern in accordance with the increase or decrease of the mineral mixture; (2) for basalt-gypsum and basalt-jarosite, the variation of the reflectance percentage does not always follow a progressive pattern in accordance with the increase or decrease of the mineral mixture; (3) for basalt-smectite, the basaltic volcanic matrix is masked, at specific working ranges, by the water-related mineral; 
(4) for basalt-opal the variation of the reflectance percentage differs significantly for the whole spectrum at different data acquisition working ranges of the GT sensor (Fig. 3b), and (5) for complex mixtures (e.g. basalt-magnetite-smectite) all types of variations are found. These results unequivocally confirm the necessity of taking into account the chemical-mineralogical assemblages (and textures) for any study and interpretation of Mars surface environment. Finally, it is important to note that there are some complementary aspects of this research, which have direct applications on our planet, either in relation to the specific performances and characteristics of the GT-sensor autonomous recalibration system, or those oriented to carrying out similar studies on different types of terrestrial environmental settings. In the first case, some examples would be air condition systems or temperature monitoring of train and car wheels and brakes (and, in general, commercial applications with intensive use of contactless temperature sensors), in which recalibration of individual sensors would imply a high cost. ${ }^{24}$ In the second, a perfect application which is currently tested ${ }^{22}$ would be the environmental monitoring systems that are deployed in extreme and remote places (e.g. Antarctica, volcanic and geothermal areas), with long working times, where access for recalibrating is
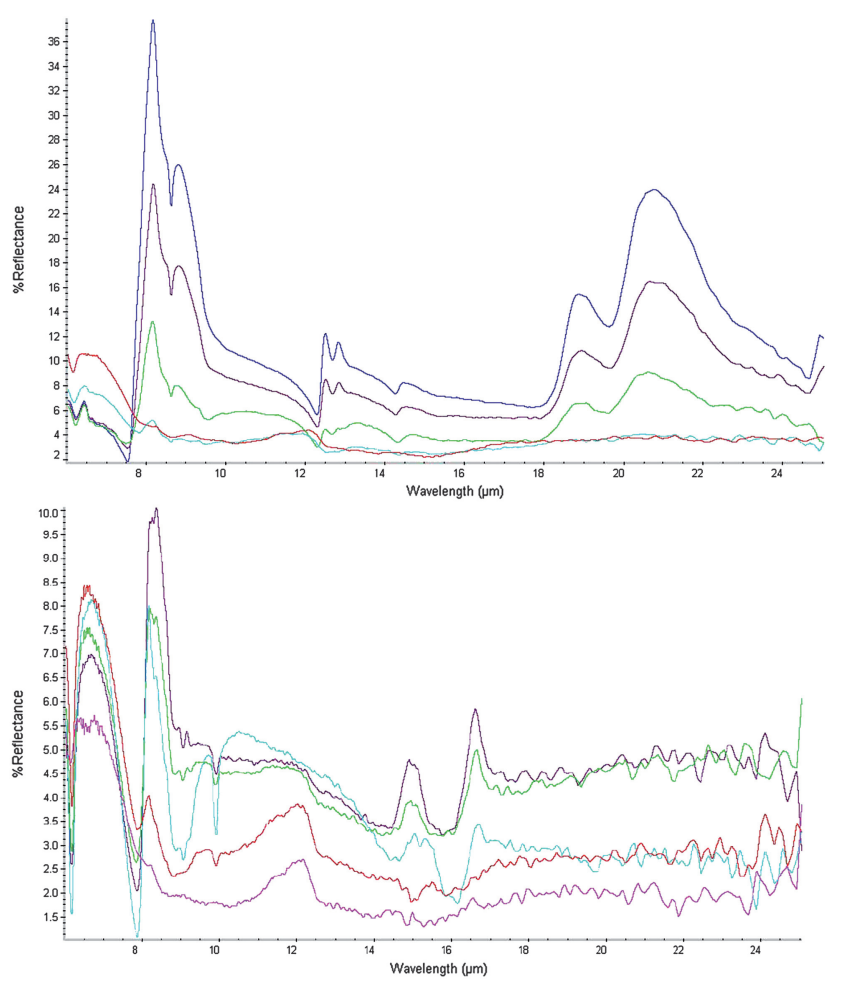

Fig. 3 Mixture of Basalt-Opal (top) and Basalt-Gypsum (bottom). Note, in the first case, that the variation of the reflectance percentage differs significantly for the whole spectrum at different data acquisition working ranges of the GT sensor (red: 100\% Basalt; light blue: $75 \%$ Basalt, 25\% Opal; green: 50\% Basalt, 50\% Opal; purple: 25\% Basalt, 75\% Opal; dark blue: $100 \%$ Opal). In the case of the basalt-gypsum mixture, the variation of the reflectance percentage does not always follow a progressive pattern in accordance with the increase or decrease of the mineral mixture (pink: 100\% Basalt; blue: 100\% Gypsum; red: $75 \%$ Basalt, 25\% Gypsum; green: 50\% Basalt, 50\% Gypsum; purple: 25\% Basalt, 75\% Gypsum). complicated and expensive. Further potential applications include, among others, solid waste deposit profiles, ${ }^{25}$ remote sensing and monitoring studies regarding disaggregation of rocks (e.g. granites) through thermal fatigue, ${ }^{26}$ ecotoxicological studies of sediments from marine environments ${ }^{27}$ and, in general terms, other studies on environmental mineralogy, which are based on the application of FTIR and mineral sciences to understanding low temperature earth surface processes, especially those involving the biosphere. ${ }^{28}$

\section{Acknowledgements}

This work forms part of the research project regarding the design and scientific issues of the NASA/MSL REMS. Thanks to the Spanish "Centro de Astrobiologia" and "Ministerio de Ciencia e Innovación" for their institutional and financial support. Thanks also to all Co-Is and collaborators of REMS, for their always fruitful remarks. Finally, thanks to Dr David Hochberg for the revision of the English version.

\section{References}

1 R. B. Singer, R. N. Clark, T. B. McCord, J. B. Adams and R. L. Huguenin, J. Geophys. Res, 1979, 84, 8415-8426.

2 D. M. Wieliczka, S. Weng and M. R. Querry, Appl. Opt., 1989, 28, $1714-1719$.

3 R. E. Milliken and J. F. Mustard, Icarus., 2007, 189-2, 550-573.

4 E. A. Cloutis, M. A. Craig, R. V. Kruzelecky, W. R. Jamroz, A. Scott, F. C. Hawthorne and S. A. Mertzman, Icarus, 2008, 195, 140-168.

5 J. L. Bandfield, J. Geophys. Res., 2002, 107, 5042.

6 J. Martinez-Frias, G. Amaral and L. Vázquez, Rev. Environ. Sci. Biotechnol., 2006, 5, 219-231.

7 J. Martínez-Frías, E. Lázaro and A. Esteve-Núñez, AMBIO: J. Hum. Environ., 2007, 36-5, 425-427.

8 L. Bethany, J. F. Ehlmann, S. L. Mustard, F. P. Murchie, J. L. Bishop, A. J. Brown, W. M. Calvin, R. N. Clark, D. J. Des Marais, R. E. Milliken, L. H. Roach, T. L. Roush, G. A. Swayze and J. J. Wray, Science, 2008, 322, 1828-1832.

$9 \mathrm{http}: / / \mathrm{mars} . j p l . n a s a . g o v / \mathrm{msl} /$.

10 J. Gómez-Elvira, and REMS Team, 2008, LPSC XXXIX 1647.pdf.

11 S. Schumacher, D. Breuer and K. Seiferlin, EGS - AGU - EUG Joint Assembly, Nice, France, 2003, abstract \#8734.

12 L. P. Maxe, LPSC XXXIX, 2008, 2002.pdf.

13 M. D. Dyar, M. W. Schaefer, J. L. Griswold, K. M. Hanify and Y. Rothstein LPSC XXXV, 2004 1356.pdf.

14 F. Esposito, L. Colangeli and E. Palomba, J. Geophys. Res., 2000, 105(E7), 17643-17654.

15 M. S. Anderson, J. M. Andringa, R. W. Carlson, P. Conrad, W. Hartford, M. Shafer, A. Soto and A. I. Tsapin, Rev. Sci. Instrum., 2005, 76, 034101.

16 B. Sutter, A. J. Brown and C. R. Stoker, Astrobiology., 2008, 8(5), $1049-1060$.

17 C. R. Stoker, H. N. Cannon, S. E. Dunagan, L. G. Lemke, B. J. Glass, D. Miller, J. Gomez-Elvira, K. Davis, J. Zavaleta, A. Winterholler, M. Roman, J. A. Rodriguez-Manfredi, R. Bonaccorsi, M. S. Bell, A. Brown, M. Battler, B. Chen, G. Cooper, M. Davidson, D. Fernández-Remolar, E. Gonzales-Pastor, J. L. Heldmann, J. Martínez-Frías, V. Parro, O. Prieto-Ballesteros, B. Sutter, A. C. Schuerger, J. Schutt and F. Rull, Astrobiology, 2008, 8(5), 921-945.

18 T. Encrenaz, E. Lellouch, J. Rosenqvist and P. Bouchet, Planetary and Space Science, 1991, 39(1-2), 267-272.

19 A. P. Zent, T. L. Hudson, M. H. Hecht, D. Cobos and S. E. Wood., 40th LPSC, 2009, 1125.pdf.

20 H. Kieffer, G. Neugebauer, G. Munch, J. R. Chase and E. Miner, Icarus, 1972, 16, 47-56.

21 L. P. Daniel, NASA technical memorandum, 1990, 102578, 1-14. 
22 M. Ramos, J. Gómez-Elvira, E. Sebastian, J. Martín, C. Armiens, J. J. Blanco, M. A. de Pablo, D. Tomé, Proc. of EGU General Assembly, 2008, 10, EGU2008-A-01434.

23 T. Spohn, K. Seiferlin, A. Hagermann, J. Knollenberg, A. Ball, M. Banaszkiewicz, J. Benkhoff, S. Gadomski, W. Gregorczyk, J. Grygorczuk, M. Hlond, G. Kargl, E. Kührt, N. Kömle, J. Krasowski, W. Marczewski and J. Zarnecki, Science Reviews, 2007, 128, 339-362.

24 M. Liess, A. Charlebois, M. Hausner, H. Ernst, H. Kragözoglu and J. Schilz., Proc. of SPIE Photonic Applications for Aerospace, Transportation and Harsh Environments, 2006, p. 6379.

25 E. Smidt, K. Meissl and J. Tintner, J. Environ. Monit., 2007, 9-12, 1387-1393.
26 M. Gómez-Heras, B. J. Smith and R. Fort, Geomorphology., 78: (3-4), pp. 236-249.

27 M. Mecozzi, M. Pietroletti and R. Di Mento, Vib. Spectrosc., 2007, 44-2, 228-235.

28 R. A. Wogelius, P. M. Morris, M. A. Kertesz, E. Chardon, A. I. R. Stark, M. Warren and J. R. Brydie, Eur. J. Mineral., 2007, 19-3, 297-307.

29 J. Martínez-Frías, R. Lunar, J. A. Rodríguez-Losada and A. Delgado, Earth, Planets Space, 2004, 56, 5-8.

30 R. L. Frost, D. Wain, B. J. Reddy, W. Martens, J. Martinez-Frias and F. Rull, J. Near Infrared Spectrosc., 2006, 14, 167-178.

31 R. L. Frost, M. Weiera, J. Martinez-Frias, F. Rull and R. B. Jagannadha Reddya, Spectrochim. Acta, Part A, 2007, 66-1, 177-183. 